\title{
Treatment of Type 2 Diabetes in Youth
}

Amanda Flint, mD

Silva Arslanian, MD

$\mathbf{T}$ ype 2 diabetes is becoming more common among youth, in parallel with the increasing prevalence of obesity in pediatrics. Despite this, therapeutic modalities remain extremely limited, with scanty data regarding appropriate treatment, desired glycemic targets, and management of associated comorbidities and complications. Management of type 2 diabetes in youth, both acute and long term, should occur in specialty tertiary care pediatric centers. Health care providers should address the pathophysiological components of insulin resistance and decline in $\beta$-cell function, aiming to preserve the latter while improving the former. Addressing comorbidities, namely hypertension and dyslipidemia, which are currently inadequately addressed, should be properly assessed and tracked. Further research is critical to establish treatment goals and develop effective diabetes management strategies that will not only enhance adherence to treatment recommendations, but also effectively manage comorbidities and prevent micro- and macrovascular complications.

With the escalating rates of obesity, type 2 diabetes is increasing $(1,2)$, not only in adults but also in youth. In the SEARCH for Diabetes in Youth study, it is estimated that the number of adolescents per year diagnosed with type 2 diabetes is $\sim 3,700$ and increasing $(2,3)$. Despite this, there is a dearth of approved therapeutic options.

The UK Prospective Diabetes Study showed that intensive glucose therapy for adults with newly diagnosed type 2 diabetes was associated with a decreased risk of microvascular complications and, among individuals who were $>120 \%$ above their ideal body weight, with a decreased risk of myocardial infarction and death from any cause (4). In patients diagnosed with type 2 diabetes at a younger age, there may be more aggressive development of diabetes complications, including myocardial infarction and microalbuminuria (5). Given these considerations, it is critical to have treatment options for adolescents with type 2 diabetes that optimize diabetes control and reduce complications. Despite the pressing need for effective treatment for adolescents with type 2 diabetes, there have been only a very limited number of clinical trials investigating pharmacotherapy for type 2 diabetes in this population. Most of the guidelines recommended for the treatment of type 2 diabetes in childhood are extrapolated from experience in adults (6). This article summarizes the body of knowledge regarding type 2 diabetes in adolescents, with particular attention to therapy for both the disease itself along with its comorbidities and complications.

PATHOPHYSIOLOGY - Type 2 diabetes is a heterogeneous disorder that results from a combination of peripheral and hepatic insulin resistance together with $\beta$-cell failure (1). Limited evidence suggests that the pathophysiology of type 2 diabetes in children is similar to adults. The earliest abnormality in the development of youth with type 2

\footnotetext{
$\bullet \bullet \bullet \bullet \bullet \bullet \bullet \bullet \bullet \bullet \bullet \bullet \bullet \bullet \bullet \bullet \bullet \bullet \bullet \bullet \bullet \bullet \bullet \bullet \bullet \bullet \bullet \bullet \bullet \bullet \bullet \bullet \bullet \bullet \bullet \bullet \bullet \bullet \bullet \bullet \bullet \bullet \bullet \bullet \bullet \bullet \bullet \bullet \bullet$

From the Division of Weight Management and Wellness, Children's Hospital of Pittsburgh, University of Pittsburgh Medical Center, Pittsburgh, Pennsylvania, and the Division of Pediatric Endocrinology, Metabolism and Diabetes Mellitus, Children's Hospital of Pittsburgh, University of Pittsburgh Medical Center, Pittsburgh, Pennsylvania

Corresponding author: Silva Arslanian, silva.arslanian@chp.edu.

This publication is based on the presentations at the 3rd World Congress on Controversies to Consensus in Diabetes, Obesity and Hypertension (CODHy). The Congress and the publication of this supplement were made possible in part by unrestricted educational grants from AstraZeneca, Boehringer Ingelheim, BristolMyers Squibb, Daiichi Sankyo, Eli Lilly, Ethicon Endo-Surgery, Generex Biotechnology, F. Hoffmann-La Roche, Janssen-Cilag, Johnson \& Johnson, Novo Nordisk, Medtronic, and Pfizer.

DOI: $10.2337 / \mathrm{dcll}-\mathrm{s} 215$

(C) 2011 by the American Diabetes Association. Readers may use this article as long as the work is properly cited, the use is educational and not for profit, and the work is not altered. See http://creativecommons.org/ licenses/by-nc-nd/3.0/ for details
}

diabetes is insulin resistance, and the evolution of progressive $\beta$-cell failure determines the eventual outcome of diabetes (7). In fact, adolescents with type 2 diabetes have $50 \%$ lower insulin sensitivity and $\sim 75 \%$ lower first-phase insulin secretion when compared with nondiabetic adolescents matched for BMI and abdominal adiposity (Fig. 1) (8). Thus, treatment of youth with type 2 diabetes must correct or alleviate both of these abnormalities.

\section{CLINICAL PRESENTATION OF YOUTH WITH TYPE 2 \\ DIABETES - The therapeutic recom-} mendations for type 2 diabetes cannot be appreciated without a brief review of the clinical presentation. Youth with type 2 diabetes at an average age of 13.5 years (at midpuberty) present a physiologic state characterized by temporary insulin resistance (9). The clinical presentation is a wide spectrum, from asymptomatic (obese at-risk youth diagnosed during screening for type 2 diabetes), to the more typical presentation of polyuria and/or polydipsia (with or without weight loss), blurry vision, monilial vaginitis in females, etc., to critically ill individuals presenting with diabetic ketoacidosis (DKA) or in the hyperglycemic hyperosmolar nonketotic (HHNK) state (9).

With the escalating rates of obesity in the general population, children with autoimmune type 1 diabetes are also becoming obese. The overlap in the clinical presentation between obese adolescents with type 2 diabetes and obese youth with autoimmune type 1 diabetes makes the clinical distinction difficult. Up to $33 \%$ of youth with type 2 diabetes have ketonuria at diagnosis, and 5-25\% present with DKA (6). DKA may also occur during acute intercurrent illness and should not be used as a criterion on which to base the diagnosis of type 1 versus type 2 diabetes (10). Furthermore, not infrequently, adolescents who are clinically diagnosed with type 2 diabetes have evidence of islet autoimmunity (11). Our studies demonstrate that obese youth clinically diagnosed with type 2 diabetes who have evidence of islet autoimmunity have severe insulin deficiency and $\beta$-cell failure compared with youth with type 2 diabetes and negative islet autoantibodies (12). Additionally, the former group is 

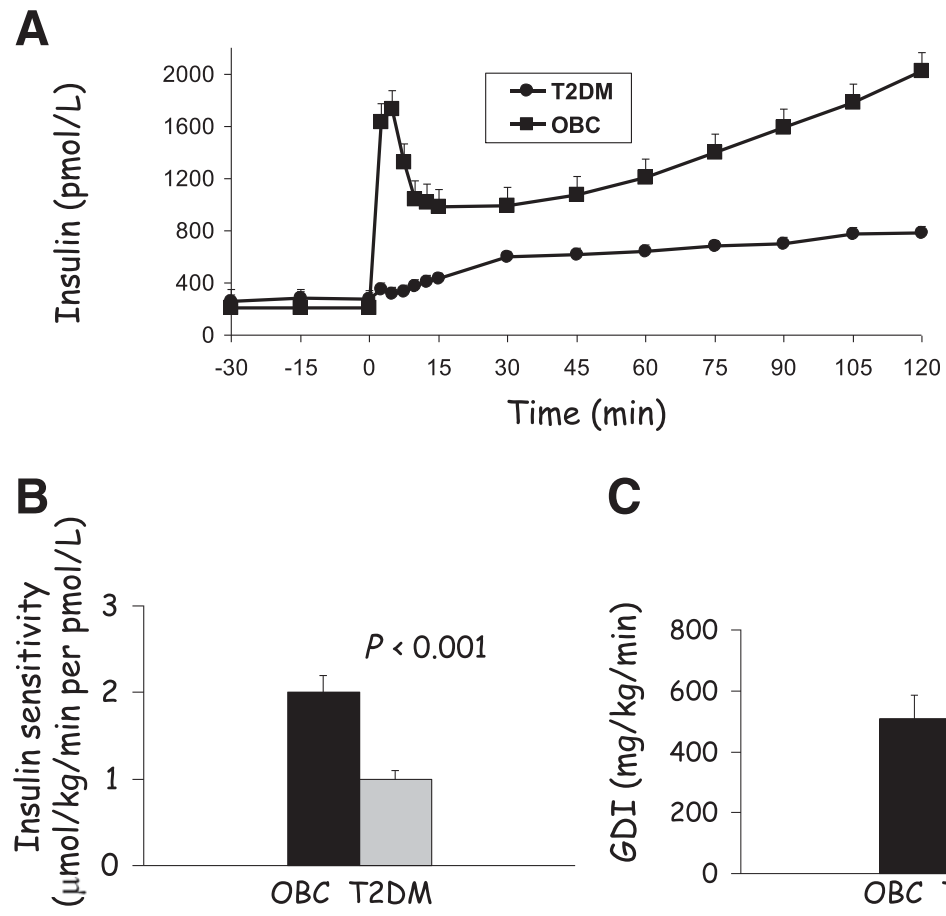

\section{C}

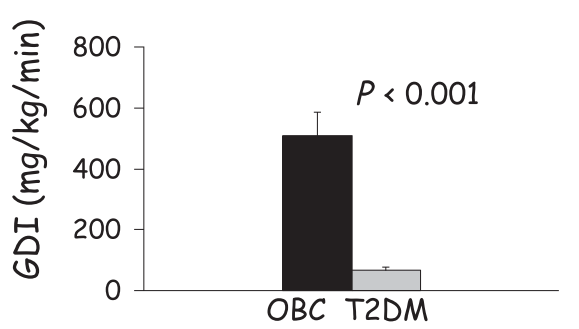

Figure 1-Insulin secretion (hyperglycemic clamp) (A), insulin sensitivity (hyperinsulinemiceuglycemic clamp) (B), and glucose disposition index (GDI) (C) in adolescents with type 2 diabetes (T2DM) compared with obese nondiabetic peers (OBC) (8). Copyright 2005 American Diabetes Association. From Gungor et al. (8). Adapted with permission from the American Diabetes Association.

not as insulin resistant as the latter, supporting the notion that the former group has autoimmune type 1 diabetes against the backdrop of obesity (12). Therefore, the absence of diabetes autoimmune markers should be a prerequisite for the diagnosis of type 2 diabetes in children and adolescents (6).

The HHNK syndrome is a lifethreatening condition occurring more commonly among youth with type 2 diabetes. In one study, 7 of 190 patients with type 2 diabetes presented in the HHNK state, and one died (13); in another review, the case-fatality rate of the HHNK state was 37\% (14). These data highlight the importance of heightened awareness and early diagnosis of type 2 diabetes in children.

ACUTE MANAGEMENT-Clearly, acute management depends on presentation. Because both DKA and especially the HHNK state are associated with high morbidity and mortality in children, early transfer to tertiary pediatric specialty care should be considered (6). DKA necessitates aggressive but cautious rehydration with introduction of insulin after initial volume expansion (15). The HHNK state, in contrast, requires much more aggressive but vigilant hydration, and insulin should be avoided until the serum glucose ceases to fall with rehydration

Patients who are not critically ill but have signs of dehydration, ketosis, severe hyperglycemia, or $\mathrm{HbA}_{1 \mathrm{c}}>8.5 \%$ require treatment with insulin to rapidly normalize the hyperglycemia and the associated glucotoxicity on insulin action and $\beta$-cell function and the consequent metabolic derangements (9). Once the ketosis subsides, attention can shift to long-term management with implementation of lifestyle changes, metformin, and/or other agents, as is also appropriate for individuals with a less severe presentation $(6,16)$.

\section{TREATMENT OF YOUTH WITH} TYPE 2 DIABETES-The treatment of type 2 diabetes necessitates a multifaceted approach to alleviate both insulin resistance and $\beta$-cell failure, achieve glycemic control, and prevent ensuing complications. This approach should include family-based behavioral lifestyle intervention together with pharmacotherapy, with the objectives of weight loss or prevention of continued weight gain, adoption of healthier lifestyle habits, normalization of glycemia, and control of alone (14). comorbidities such as hypertension, dyslipidemia, nephropathy, and hepatic steatosis (17).

Current management guidelines for youth with type 2 diabetes are not evidence-based because of the lack of clinical trials, and the majority of treatment recommendations are based on experience in adults. Irrespective of this, it appears that almost all adolescents achieve normalization of $\mathrm{HbA}_{1 \mathrm{c}}$, at least initially, regardless of the severity of type 2 diabetes manifestation and the initial treatment modality (18), which may vary significantly among pediatric endocrinologists (19). Moreover, a large percentage of adolescents with type 2 diabetes, up to $60 \%$, are lost to follow-up at diabetes care centers (18). Therefore, efforts should be geared to individualize therapy in type 2 diabetes not only based on phenotype and genotype (20), but also based on ethnic/ cultural beliefs and traditions.

\section{Lifestyle modification of nutritional and activity habits}

Change in lifestyle habits remains an important component in the management of the child and adult with type 2 diabetes. Several diabetes prevention trials in adults demonstrate that lifestyle intervention, consisting of increased physical activity and dietary modification with lower caloric intake and weight loss, reduces the rate of progression to type 2 diabetes in people with impaired glucose tolerance (21). There are no such studies in pediatrics, nor are there studies in youth with type 2 diabetes that have compared the effectiveness of lifestyle intervention alone to pharmacotherapy. However, based on observations in adults, the current recommendation in the management of the adolescent with type 2 diabetes includes both dietary and exercise modification. Successful treatment is defined by cessation of excessive weight gain with normal linear growth (6), although in most cases, weight loss is desirable (17). Ideally, care should include guidance by a nutritionist (16), with elimination of sugar-containing beverages and high-fat high-calorie foods, establishment of a regular meal schedule, portion control, and improvement in food choices (14). Recommended exercise goals include decreasing sedentary activity, such as time spent watching television and using the computer, and increasing energy expenditure through incorporating daily habits of increased activity, such as using the stairs 
and walking as a mode of transportation (22). Such lifestyle modifications should be family-centered because studies in obese nondiabetic youth show better short- and long-term outcome when the intervention involves both the child and the family (23).

The proportion of youth with type 2 diabetes treated with lifestyle modification alone ranges from 11 to $50 \%$ $(18,24,25)$. Among patients treated solely with lifestyle modification, only $17 \%$ experienced a reduction in SDS-BMI during at least a 1-year period, and only $23 \%$ remained off of antidiabetes therapy over a 2 -year period (18). Additionally, $65 \%$ of patients treated with lifestyle modification alone were lost to follow-up (18), which is clearly not ideal.

\section{Pharmacotherapy of youth with type 2 diabetes}

At the present time, metformin is the only U.S. Food and Drug Administration (FDA)-approved oral treatment for youth with type 2 diabetes (26), and this is true among other countries as well (17). In a randomized placebo-controlled trial of metformin in adolescents with new-onset type 2 diabetes, metformin treatment resulted in a significantly lower $\mathrm{HbA}_{1 \mathrm{c}}$ after 16 weeks compared with placebo (7.5 vs. 8.6\%) (27). In addition, fasting plasma glucose improved by $2.4 \mathrm{mmol} / \mathrm{L} \mathrm{com}$ pared with an increase of $1.2 \mathrm{mmol} / \mathrm{L}$ with placebo. Moreover, there were no safety issues or untoward effects of metformin. Subjects in the study were titrated to a maximum tolerated dose of medication, up to $2,000 \mathrm{mg} / \mathrm{day}$, with $83 \%$ of patients reaching this goal, with an average daily dose among study participants of $1,798 \mathrm{mg}$ (27). This study led to the FDA approving metformin in youth with type 2 diabetes, and both the American Diabetes Association (ADA) and International Society for Pediatric and Adolescent Diabetes (ISPAD) guidelines recommend metformin as the first-line oral antidiabetic drug $(6,17)$. However, surveys of practicing physicians, including pediatric endocrinologists, indicate a wide range for the use of metformin in youth with type 2 diabetes $(28-71 \%)(24,25,28)$. Also, a wide range of doses are reported, although it is often suggested that the medication be titrated to a maximum dose of 2,000 $\mathrm{mg} /$ day, divided twice daily, based on effectiveness and tolerance of side effects $(27,28)$.

Youth with type 2 diabetes who present with severe hyperglycemia ( $\geq 11.1$ $\mathrm{mmol} / \mathrm{L}), \mathrm{HbA}_{1 \mathrm{c}}>8.5 \%$, or severe manifestations of insulin deficiency such as ketosis or DKA should be treated initially with insulin for rapid metabolic control (9). There is mounting evidence that aggressive reduction of glycemia, particularly with insulin, in adults with newly diagnosed type 2 diabetes can result in sustained remission (29). In pediatrics, the data are scant. The short-term use of insulin ( $<16$ week duration) in poorly controlled adolescents with type 2 diabetes, using premixed 70/30 insulin given twice daily, was associated with significant improvement in $\mathrm{HbA}_{\mathrm{lc}}$ without significant change in BMI or hypoglycemia. Interestingly, this effect persisted for 12 months after insulin was discontinued without additional medications (30). Insulin regimens should be individualized based on patient characteristics, family dynamics, adherence, etc. (17), although a single daily injection of insulin glargine has been shown to be effective in adults (31). Insulin may be prescribed as the initial and/or the only therapy for youth with type 2 diabetes, with surveys showing between 8 and $72 \%$ of youth receiving insulin alone $(24,25,28)$. Despite the goal of withdrawing insulin therapy after its initial introduction, only $28 \%$ of patients were able to come off insulin, and of those, $60 \%$ required reinitiation of insulin because of poor control (28). It should be noted that the use of insulin for optimal blood glucose control is accompanied by excessive weight gain and the risk of hypoglycemia (32). Adherence rates to

multiple daily injections of insulin have been lower than other hypoglycemic agents in studies involving adults and children (33), and, thus, while insulin can be effective, its drawbacks necessitate consideration of alternative or adjunctive therapy options.

It is our clinical impression that the majority of adolescents with type 2 diabetes maintain glycemic control for the first 2-3 years, with an $\mathrm{HbA}_{1 \mathrm{c}}<7 \%$, while using metformin and lifestyle intervention (S.A., personal communication). However, once glycemic control fails, additional agents, and typically insulin, are considered (Fig. 2). Insulin is added as a bedtime long-acting analog (glargine or detemir) at a dose of 0.3-0.4 units $/ \mathrm{kg} /$ day. If this fails, the remaining options are limited and restricted to using various insulin regimens. At our center, we avoid using drugs that are not FDA approved, including thiazolidinediones (TZDs) and insulin secretagogues. However, this is not the case for other providers. Surveys show that $\sim 50 \%$ of youth were treated with secretagogues in 2000 and $28 \%$ in 2008 , and $9 \%$ were treated with TZDs in $2000(24,25,28)$. A randomized controlled trial of glimepiride, a sulfonylurea insulin secretagogue, versus metformin for 24 weeks, showed comparable reductions in $\mathrm{HbA}_{1 \mathrm{c}}$; however, BMI and weight gain was significantly higher in the glimepiride group (34). When confronted with the management of youth with type 2 diabetes who have severe obesity, the weight gain and hypoglycemic side effects

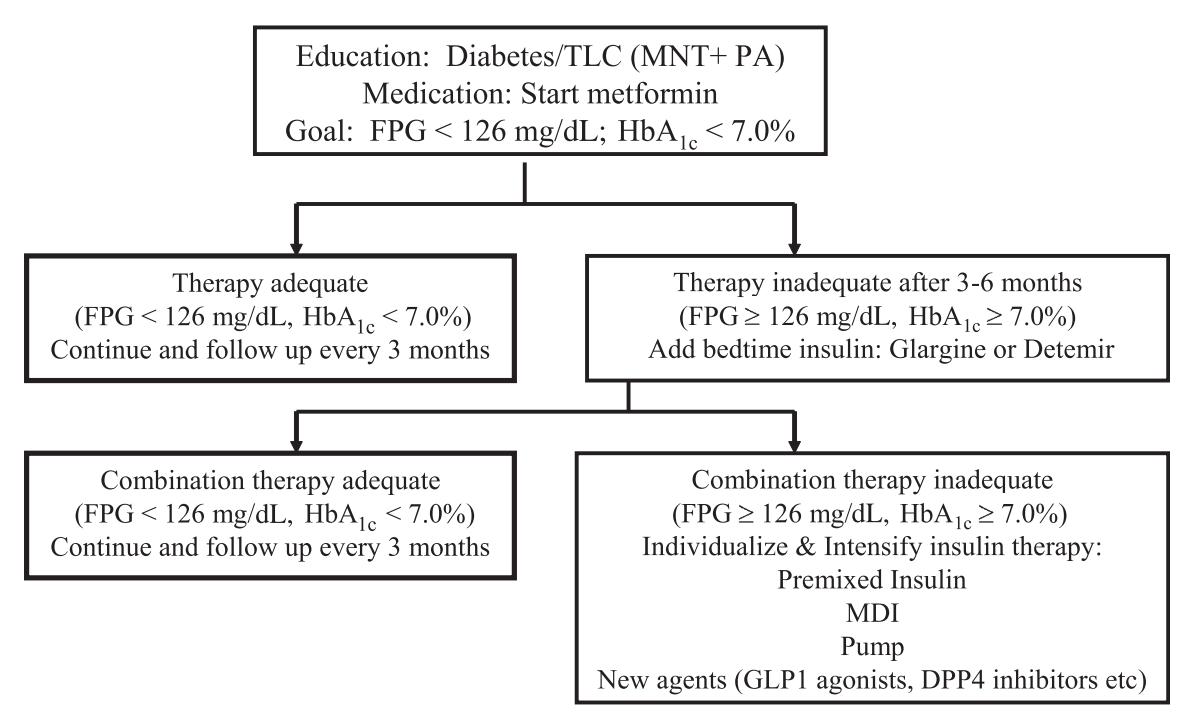

Figure 2-Treatment algorithm for type 2 diabetes in adolescents. Adapted with permission from Gungor et al. (9). DPP4, dipeptidyl peptidase-4; FPG, fasting plasma glucose; MDI, multiple daily injection; MNT, medical nutrition therapy; PA, physical activity; TLC, therapeutic lifestyle change. 
of sulfonylureas make them a less desirable therapeutic choice. A randomized double-blind trial of rosiglitazone versus metformin for 24 weeks in adolescents with type 2 diabetes demonstrated similar reductions in $\mathrm{HbA}_{1 \mathrm{c}}$. However, there was an $\sim 3 \mathrm{~kg}$ weight gain in the rosiglitazone group with mild peripheral edema in one subject (35). In the presence of significant scientific discord in the adult literature about the safety and use of rosiglitazone (36), caution should be used when considering TZDs in children, particularly in the absence of regulatory approval (17). Two other classes of drugs, glinides (repaglinide and nateglinide, short-acting insulin secretagogues) and glucosidase inhibitors (acarbose), are available for adults (17) but are not approved in pediatrics. In 2000, $4 \%$ of adolescents with type 2 diabetes were using glucosidase inhibitors (24). Because these drugs necessitate dosing before all meals, adherence may be limited. Also, the frequent side effect of flatulence limits their acceptability to adolescents (17).

On the horizon, therapeutic options that may prove beneficial for pediatric patients with type 2 diabetes are the incretin-based therapies. The incretin hormone targeted for diabetes therapy is glucagon-like peptide (GLP)-1, which is secreted from the L-cells of the intestines and affects glycemic control by augmenting glucose-dependent secretion of insulin, suppressing glucagon secretion in the postprandial period, slowing gastric emptying, and increasing satiety (37). Here again, data in pediatrics is almost nonexistent. The first GLP-1 receptor agonist approved in adults was exenatide, which besides lowering $\mathrm{HbA}_{1 \mathrm{c}}$, has the added benefit of mild weight loss (38). A pharmacokinetics and safety study of exenatide, given as a single injection in adolescents with type 2 diabetes, was well tolerated and improved postprandial glucose concentration, thus holding promise in this population (39). Currently, there is an ongoing multicenter efficacy and safety trial of exenatide in adolescents with type 2 diabetes. In our opinion, twicedaily injections of exenatide will not be a welcomed therapeutic choice by adolescents with type 2 diabetes, especially considering the low rates of adherence to therapeutic recommendations in this population (18). A more promising option would be the long-acting once-weekly injection formulation of exenatide, currently in the process of obtaining drug regulatory agency approval in adults, showing overall improvements in $\mathrm{HbA}_{1 \mathrm{c}}$ by as much as $1.9 \%$, with weight loss of up to $4.0 \mathrm{~kg}$ (38). Although a once-weekly regimen may be more convenient for adolescents, until such time that the results of randomized controlled trials are available in this population, its use is not recommended. Liraglutide, another GLP-1 receptor agonist, recently approved in the U.S. and Europe, shows a reduction in $\mathrm{HbA}_{1 \mathrm{c}}$ up to $1.8 \%$ and weight loss of up to $4.5 \mathrm{~kg}$ in adults with type 2 diabetes (38). Liraglutide also improved $\beta$-cell function, a desirable treatment goal (38). However, at the moment, there are no study outcomes of liraglutide in adolescents with type 2 diabetes. A related class of medications is the dipeptidyl peptidase-4 inhibitors, which lead to increased endogenous GLP-1 (37). Currently, there are no data on the use of dipeptidyl peptidase-4 inhibitors in pediatrics.

It is clear from the above that, while there are myriad options for pharmacotherapy for adults with type 2 diabetes, data remain extremely limited in pediatrics. It is imperative that well-designed studies be implemented in this population to better understand how best to treat type 2 diabetes. One such trial, Treatment Options for Type 2 Diabetes in Adolescents and Youth (TODAY), a 15-center National Institutes of Health trial, is underway in 704 10- to 17-year-old participants who were randomized to either metformin together with placebo, metformin together with rosiglitazone, or metformin together with lifestyle intervention (40). TODAY will be completed in 2011, and its results will play a significant role in our understanding of the efficacy of these three therapeutic options in maintaining glycemic control and preserving $\beta$-cell function in this age group.

\section{Bariatric surgery}

Roux-en-Y gastric bypass (RYGB) is a surgical technique promoted as a safe and effective option for adolescent weight loss (41). Currently, eligibility criteria for adolescents include a BMI $>35 \mathrm{~kg} / \mathrm{m}^{2}$ if a serious comorbidity (such as type 2 diabetes) is also present, Tanner stage IV or $\mathrm{V}$, and skeletal maturity (41). Studies in adults show remission of type 2 diabetes in $85 \%$ of subjects who underwent RYGB (42). In one retrospective study of only 11 adolescents with type 2 diabetes who underwent RYGB compared with individuals who were medically managed, RYGB resulted in greater decrements in BMI
( $\sim 34 \%)$ and improvement in diabetes control, hyperlipidemia, and hypertension (42). All but one of the surgically treated patients experienced remission of their diabetes without the need for medication. However, considering the very small study size and short duration of observation, one must exercise caution before adopting such an approach for the treatment of type 2 diabetes in youth until results from larger and longer wellcontrolled studies become available. Adjustable gastric banding is another less invasive technique but is not approved in pediatrics (41).

\section{MANAGEMENT OF COMORBIDITIES AND COMPLICATIONS-Comorbidities,} characteristic of the insulin resistance syndrome, are already seen at the time of diagnosis of type 2 diabetes in adolescents, unlike in type 1 diabetes, where these conditions are complications of diabetes (17). In one study, $49 \%$ of young people with diabetes had systolic hypertension at presentation, a rate eight times higher than in type 1 diabetes (5). Additionally, in the SEARCH study, microalbuminuria was more prevalent in youth with type 2 diabetes (22.2\%) compared with youth with type 1 diabetes (9.2\%) (43). Moreover, microalbuminuria was detected at diagnosis in 22\% of Pima Indians with youth-onset type 2 diabetes, with a much higher incident rate of endstage renal disease among this group compared with individuals with adult-onset disease (44). Importantly, the rate of progression of microalbuminuria seems to be more rapid in adolescents with type 2 diabetes (5), making early detection and intervention important to prevent declining kidney function. Dyslipidemia, a major comorbidity of obesity, is present in high rates in youth with type 2 diabetes, ranging from 18 to $61 \%$ at diagnosis (5). Considering these high rates of cardiovascular disease risk factors, it is not surprising that early signs of cardiovascular disease have been reported in youth with type 2 diabetes, typically showing increased arterial stiffness and/or left ventricular hypertrophy $(5,45,46)$.

Interventions aimed at these comorbidities, in addition to achieving glycemic goals, are important to prevent long-term morbidity and mortality in youth with type 2 diabetes (Fig. 3). It should be noted, though, that there are no evidence-based guidelines for glycemic goals in youth with type 2 diabetes. However, based on 


\section{Health-Management Skills}

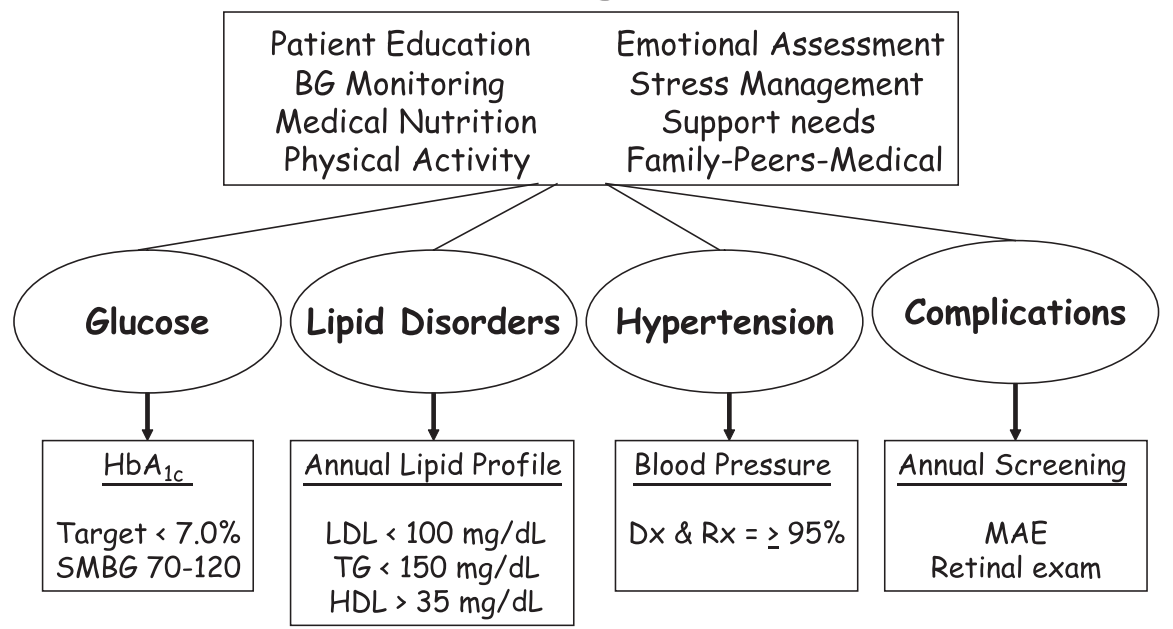

Figure 3-Comprehensive/global care of youth with type 2 diabetes. Adapted with permission from Libman et al. (16). Copyright S. Karger AG, Basel, Switzerland. BG, blood glucose; $D x$, diagnosis; MAE, microalbumin excretion; $R x$, treatment; SMBG, self-monitored blood glucose; TG, triglycerides.

the adult experience and data from the Diabetes Control and Complications Trial in adolescents with type 1 diabetes, it is logical to aim to achieve as near-normal glycemia as possible. Results of the UK Prospective Diabetes Study demonstrate that the incidence of diabetes-related micro- and macrovascular disease increases with increasing $\mathrm{HbA}_{1 \mathrm{c}}$ levels (47). Furthermore, intensive glucose control in adults with newly diagnosed type 2 diabetes is associated with a reduced risk of micro- and macrovascular complications (4), and these benefits appear to persist over time among individuals aggressively treated initially, even as the differences in glycemic levels wane (48). Guided by such findings, the current recommendations for a target $\mathrm{HbA}_{1 \mathrm{c}}$ are $<7.0 \%$ by the ADA and $\operatorname{ISPAD}(6,17)$ and $<6.5 \%$ by the International Diabetes Federation (49). For the management of hypertension, blood pressure tables (50) must be used for diagnosis of hypertension because, unlike in adults, an absolute cutoff for blood pressure is not applicable to pediatrics. Hypertension in pediatrics (blood pressure $>95 \%$ for age, sex, and height, especially in conjunction with albuminuria) should be treated aggressively, since effective therapy in these patients can prolong the time to end-stage renal disease (51). If tolerated, an ACE inhibitor should be used; otherwise, an angiotensin receptor blocker should be used (17). Recommended management of microalbuminuria is similar, although there are concerns regarding use of ACE inhibitors in individuals without hypertension, given the side effects and likely duration of use, and among women, with the risks to potential pregnancies (51).

Hyperlipidemia should also be managed aggressively, with a goal of LDL $<100 \mathrm{mg} / \mathrm{dL}$, triglycerides $<150 \mathrm{mg} / \mathrm{dL}$, and HDL $>35$ mg/dL (Fig. 3) $(16,17,52$ ). Treatment strategies include maximizing nonpharmacologic interventions for LDL of $100-129 \mathrm{mg} / \mathrm{dL}$, considering medication on the basis of presence of other risk factors for LDL of 130-159 mg/dL, and initiating medication for LDL $>160 \mathrm{mg} / \mathrm{dL}$ (52). Statin therapy has been shown to be safe and effective in youth and should be the first pharmacologic intervention (17), with bile acid sequestrants also considered (52). If triglycerides are $\geq 1,000$ $\mathrm{mg} / \mathrm{dL}$, treatment with fibric acid should be considered to reduce the risk of pancreatitis (52).

Despite these recommendations, there is still lack of proper attention to and treatment of these comorbidities. In one report of diabetes centers' experience, $<5 \%$ of all youth with type 2 diabetes were treated for hypertension or dyslipidemia, despite the fact that $65 \%$ had hypertension and $44 \%$ had dyslipidemia (18). Patients should also have annual screening for microalbuminuria and retinopathy. However, the high attrition rate of adolescents with type 2 diabetes from diabetes clinics is a major barrier. In one study, $60 \%$ of children with type 2 diabetes dropped out of care after a mean of 7.1 months (18).

\section{SUMMARY AND}

CONCLUSION_The comprehensive treatment of youth with type 2 diabetes should target the metabolic derangements underlying and associated with the disease, including obesity, insulin resistance, insulin deficiency, dyslipidemia, hypertension, and early complications. The traditional glucocentric approach that characterizes the treatment of children with type 1 diabetes will fall short of expectations in the management of youth with type 2 diabetes. Efforts should be mobilized to enrich the limited therapeutic armamentarium with newer drugs for youth with type 2 diabetes. GLP-1 receptor agonists are especially promising and should be tested in this population without delay. Individualizing treatment regimens should be given consideration, bearing in mind the higher rates of type 2 diabetes in minority children. Lastly, research is needed to generate evidencebased recommendations for glycemic goals and the prevention of micro- and macrovascular complications in adolescents with type 2 diabetes.

Acknowledgments-This work was supported by T32 Grant DK-007729 (to A.F.) and K24 Grant HD-01357 (to S.A.).

No potential conflicts of interest relevant to this article were reported.

\section{References}

1. Zeitler P. Update on nonautoimmune diabetes in children. J Clin Endocrinol Metab 2009;94:2215-2220

2. Writing Group for the SEARCH for Diabetes in Youth Study Group, Dabelea D, Bell RA, et al. Incidence of diabetes in youth in the United States. JAMA 2007; 297:2716-2724

3. Nadeau K, Dabelea D. Epidemiology of type 2 diabetes in children and adolescents. Endocr Res 2008;33:35-58

4. Hillier TA, Pedula KL. Complications in young adults with early-onset type 2 diabetes: losing the relative protection of youth. Diabetes Care 2003;26:2999_ 3005

5. Pinhas-Hamiel O, Zeitler P. Acute and chronic complications of type 2 diabetes mellitus in children and adolescents. Lancet 2007;369:1823-1831

6. American Diabetes Association. Type 2 diabetes in children and adolescents. Diabetes Care 2000;23:381-389 
7. Candido C, Bacha F, Hannon T, Libman I, Arslanian S. Obesity and type 2 diabetes in children. In Therapy for Diabetes Mellitus and Related Disorders. 5th ed. Lebovitz HE, Ed. Alexandria, VA, American Diabetes Association, 2009

8. Gungor N, Bacha F, Saad R, Janosky J, Arslanian S. Youth type 2 diabetes: insulin resistance, beta-cell failure, or both? Diabetes Care 2005;28:638-644

9. Gungor N, Hannon T, Libman I, Bacha F, Arslanian S. Type 2 diabetes mellitus in youth: the complete picture to date. Pediatr Clin North Am 2005;52:1579-1609

10. Rewers A, Klingensmith G, Davis C, et al. Presence of diabetic ketoacidosis at diagnosis of diabetes mellitus in youth: the Search for Diabetes in Youth Study. Pediatrics 2008;121:e1258-e1266

11. Gilliam LK, Brooks-Worrell BM, Palmer JP, Greenbaum CJ, Pihoker C. Autoimmunity and clinical course in children with type 1 , type 2 , and type 1.5 diabetes. J Autoimmun 2005;25:244-250

12. Tfayli H, Bacha F, Gungor N, Arslanian S. Phenotypic type 2 diabetes in obese youth: insulin sensitivity and secretion in islet cell antibody-negative versus -positive patients. Diabetes 2009;58:738-744

13. Fourtner SH, Weinzimer SA, Levitt Katz LE. Hyperglycemic hyperosmolar nonketotic syndrome in children with type 2 diabetes. Pediatr Diabetes 2005;6:129_ 135

14. Rosenbloom AL. Hyperglycemic hyperosmolar state: an emerging pediatric problem. J Pediatr 2010;156:180-184

15. Wolfsdorf J, Craig ME, Daneman D, et al. Diabetic ketoacidosis in children and adolescents with diabetes. Pediatr Diabetes 2009;10(Suppl. 12):118-133

16. Libman IM, Arslanian SA. Prevention and treatment of type 2 diabetes in youth. Horm Res 2007;67:22-34

17. Rosenbloom AL, Silverstein JH, Amemiya S, Zeitler P, Klingensmith GJ. Type 2 diabetes in children and adolescents. Pediatr Diabetes 2009;10(Suppl. 12):17-32

18. Reinehr T, Schober E, Roth CL, Wiegand S, Holl R; DPV-Wiss Study Group. Type 2 diabetes in children and adolescents in a 2-year follow-up: insufficient adherence to diabetes centers. Horm Res 2008;69: 107-113

19. Wong K, Potter A, Mulvaney S, Russell WE, Schlundt DG, Rothman RL. Pediatric endocrinologists' management of children with type 2 diabetes. Diabetes Care 2010;33:512-514

20. Smith RJ, Nathan DM, Arslanian SA, Groop L, Rizza RA, Rotter JI. Individualizing therapies in type 2 diabetes mellitus based on patient characteristics: what we know and what we need to know. J Clin Endocrinol Metab 2010;95:15661574

21. Gillies CL, Abrams KR, Lambert PC, et al. Pharmacological and lifestyle interventions to prevent or delay type 2 diabetes in people with impaired glucose tolerance: systematic review and meta-analysis. BMJ 2007;334: 299-302

22. Wilfley DE, Tibbs TL, Van Buren DJ, Reach KP, Walker MS, Epstein LH. Lifestyle interventions in the treatment of childhood overweight: a meta-analytic review of randomized controlled trials. Health Psychol 2007;26:521-532

23. McLean N, Griffin S, Toney K, Hardeman W. Family involvement in weight control, weight maintenance and weight-loss interventions: a systematic review of randomised trials. Int J Obes Relat Metab Disord 2003;27:987-1005

24. Silverstein JH, Rosenbloom AL. Treatment of type 2 diabetes mellitus in children and adolescents. J Pediatr Endocrinol Metab 2000;13(Suppl. 6):1403-1409

25. Newfield RS, Dewan AK, Jain S. Dyslipidemia in children with type 2 diabetes vs. obesity. Pediatr Diabetes 2008;9:115121

26. Weigensberg MJ, Goran MI. Type 2 diabetes in children and adolescents. Lancet 2009;373:1743-1744

27. Jones KL, Arslanian S, Peterokova VA, Park J-S, Tomlinson MJ. Effect of metformin in pediatric patients with type 2 diabetes: a randomized controlled trial. Diabetes Care 2002:25:89-94

28. Zuhri-Yafi MI, Brosnan PG, Hardin DS. Treatment of type 2 diabetes mellitus in children and adolescents. J Pediatr Endocrinol Metab 2002;15(Suppl. 1):541546

29. Nathan DM, Buse JB, Davidson MB, et al. Medical management of hyperglycaemia in type 2 diabetes mellitus: a consensus algorithm for the initiation and adjustment of therapy: a consensus statement from the American Diabetes Association and the European Association for the Study of Diabetes. Diabetologia 2009;52: $17-30$

30. Sellers EA, Dean HJ. Short-term insulin therapy in adolescents with type 2 diabetes mellitus. J Pediatr Endocrinol Metab 2004;17:1561-1564

31. Bretzel RG, Nuber U, Landgraf W, Owens DR, Bradley C, Linn T. Once-daily basal insulin glargine versus thrice-daily prandial insulin lispro in people with type 2 diabetes on oral hypoglycaemic agents (APOLLO): an open randomised controlled trial. Lancet 2008;371:1073-1084

32. Raman VS, Heptulla RA. New potential adjuncts to treatment of children with type 1 diabetes mellitus. Pediatr Res 2009; 65:370-374

33. Cramer JA. A systematic review of adherence with medications for diabetes. Diabetes Care 2004:27:1218-1224

34. Gottschalk M, Danne T, Vlajnic A, Cara JF. Glimepiride versus metformin as monotherapy in pediatric patients with type 2 diabetes: a randomized, single-blind comparative study. Diabetes Care 2007;30: 790-794

35. Guissou D, Jones K, Krebs J, et al. Benefits of rosiglitazone in children with T2DM (Abstract). Diabetes 2005;54:A457

36. Schernthaner G, Barnett AH, Betteridge DJ, et al. Is the ADA/EASD algorithm for the management of type 2 diabetes (January 2009) based on evidence or opinion? A critical analysis. Diabetologia 2010;53: 1258-1269

37. Peters A. Incretin-based therapies: review of current clinical trial data. Am J Med 2010;123(Suppl.):S28-S37

38. Madsbad S. Exenatide and liraglutide: different approaches to develop GLP-1 receptor agonists (incretin mimetics): preclinical and clinical results. Best Pract Res Clin Endocrinol Metab 2009;23:463-477

39. Malloy J, Capparelli E, Gottschalk M, Guan X, Kothare P, Fineman M. Pharmacology and tolerability of a single dose of exenatide in adolescent patients with type 2 diabetes mellitus being treated with metformin: a randomized, placebocontrolled, single-blind, dose-escalation, crossover study. Clin Ther 2009;31:806815

40. Zeitler P, Epstein L, Grey M, et al. Treatment options for type 2 diabetes in adolescents and youth: a study of the comparative efficacy of metformin alone or in combination with rosiglitazone or lifestyle intervention in adolescents with type 2 diabetes. Pediatr Diabetes 2007;8: 74-87

41. Pratt JSA, Lenders CM, Dionne EA, et al. Best practice updates for pediatric/ adolescent weight loss surgery. Obesity (Silver Spring) 2009;17:901-910

42. Inge TH, Miyano G, Bean J, et al. Reversal of type 2 diabetes mellitus and improvements in cardiovascular risk factors after surgical weight loss in adolescents. Pediatrics 2009;123:214-222

43. Maahs DM, Snively BM, Bell RA, et al. Higher prevalence of elevated albumin excretion in youth with type 2 than type 1 diabetes: the SEARCH for Diabetes in Youth study. Diabetes Care 2007;30: 2593-2598

44. Pavkov ME, Bennett PH, Knowler WC, Krakoff J, Sievers ML, Nelson RG. Effect of youth-onset type 2 diabetes mellitus on incidence of end-stage renal disease and mortality in young and middle-aged Pima Indians. JAMA 2006;296:421426

45. Gungor N, Thompson T, Sutton-Tyrrell K, Janosky J, Arslanian S. Early signs of cardiovascular disease in youth with obesity and type 2 diabetes. Diabetes Care 2005;28:1219-1221

46. Wadwa RP, Urbina EM, Anderson AM, et al. Measures of arterial stiffness in youth with type 1 and type 2 diabetes: the SEARCH for diabetes in youth study. Diabetes Care 2010;33:881-886 
47. Stratton IM, Adler AI, Neil HAW, et al Association of glycaemia with macrovascular and microvascular complications of type 2 diabetes (UKPDS 35): prospective observational study. BMJ 2000;321: 405-412

48. Holman RR, Paul SK, Bethel MA, Matthews DR, Neil HAW. 10-year followup of intensive glucose control in type 2 diabetes. N Engl J Med 2008;359:15771589
49. Ceriello A, Colagiuri S. International Diabetes Federation guideline for management of postmeal glucose: a review of recommendations. Diabet Med 2008;25: 1151-1156

50. National High Blood Pressure Education Program Working Group on High Blood Pressure in Children and Adolescents. The fourth report on the diagnosis, evaluation, and treatment of high blood pressure in children and adolescents. Pediatrics 2004;114(Suppl.): 555-576

51. Donaghue KC, Chiarelli F, Trotta D, Allgrove J, Dahl-Jorgensen K. Microvascular and macrovascular complications associated with diabetes in children and adolescents. Pediatr Diabetes 2009;10(Suppl. 12):195-203

52. American Diabetes Association. Management of dyslipidemia in children and adolescents with diabetes. Diabetes Care 2003; 26:2194-2197 